\title{
Supply-Chain Coopetition
}

\author{
Hans W. Gottinger \\ Strategy Technology Economics, STRATEC Consulting, Munich, Germany
}

\section{Email address:}

stratec_c@yahoo.com

\section{To cite this article:}

Hans W. Gottinger. Supply-Chain Coopetition. International Journal of Business and Economics Research. Vol. 4, No. 2, 2015 , pp. 67-71. doi: $10.11648 /$ j.ijber.20150402.16

\begin{abstract}
This paper addresses the power struggle among supply chain partners. It is asserted that when firms are collaborating to deliver value in the market; the creation of critical asset requires more than just monopoly ownership of supply of a resource over competitors. A critical asset can only be truly owned and/or controlled effectively to leverage value if there is a dominance of one party in an exchange relationship over another. The implication is that to better understand the rent-earning capability of any supply chain resource, the relative power attributes of both buyer and supplier must be understood. Specifically these rents are earnings in excess of the firm's costs of production that are not eroded in the long run by new market entrants. In economic terms, rents persist in long-run equilibrium while profits tend towards zero.
\end{abstract}

Keywords: Supply Chain, Outsourcing, Coopetition, Investment Strategy, Stochastic Games

\section{Introduction}

The purpose of this paper is to provide a strategic framework and insights regarding power and competition in a collaborative supply chain network. It builds on strategic thinking specifically in the context of collaboration. In particular, Williamson's [1-3] transaction cost approach provides a conceptual grounding for understanding the fundamental basis on which relationship between buyer and supplier takes place. With multiple firms constituting a supply chain, investments by supply chain partners have implications that transcend the traditional cost minimization or revenue/profit maximization objectives. In present dynamic environments, firms are investing in risky innovations and associated strategies to gain first-mover advantage [4]. But also in high technology industries more firms strategically decide to enter a collaborative relationship. In a joint product development context, many firms outsource the manufacturing process of components which would be used in the final product. At times, this outsourcing goes beyond just the manufacturing of a fully specified component to allowing and expecting the supplier to build resource competence through active innovation.

In such circumstances, firms enter the crossroads of a very delicate strategic supply chain relationship. Specifically, a strategy ought to be in place to defend the ability to appropriate and accumulate value by ensuring that the suppliers of the resources that the firm chooses not to own are not able to put themselves in a position to leverage value from the firm. The PC industry provides an excellent example of power diffusion up the supply chain. In 1981 IBM designed product, process and supply chain such that it sources the microprocessors from Intel and the operating system and application software from Microsoft. The outcome was a phenomenally successful product design but a disastrous supply chain design for IBM. Today, the power of Intel in the supply chain for PCs is undisputed. The new innovations that occur in this industry are to a great extent defined by this upstream supplier of microprocessors. The lesson learnt is to be aware of the "Intel inside" syndrome [5].Also in the context of anti-trust analysis evidence of vertical innovation and its impact on competitive positioning has previously been shown by Fisher et al [6] in detail.

With increasing formation of collaborative supply chain networks, research regarding channel power and lock-in circumstances in a supply chain is of paramount importance. Cox et al. [7] highlight the need to undertake rigorous analytical research in this sphere of supply -and value chain networks to augment our understanding of power regimes. The results of an analytical research could potentially provide understanding of the types of countervailing strategy to shift the balance of power in a supply chain.

This paper analytically examines this issue using a differential games based approach.. A model of competitive dynamics between a supplier and a buyer is presented using the theory of stochastic processes and differential games. It 
analyzes the context of buyer-supplier competition, by adapting and building on Browne [8] which is primarily targeted towards investigation of portfolio investment strategies in finance. In this work, the analysis and theoretical results in Browne [8] are extended to gain insights associated with strategic supply chain management. Also we draw from a specialized survey of results by Karatzas [9]

The organization of this paper is as follows. The next section presents the model formulation. In the third section, the nature of the game is detailed. The model is analyzed in the fourth section and the results are presented in the form of theorems and propositions. Finally, the fifth section briefly discusses some results. The proofs of the theorems and propositions are provided in the Appendix.

\section{A Differential Game Model}

The notations and symbols used in the model are as follows:

S: subscript for the supplier firm

B: subscript for the buyer firm

$\mathrm{T}$ : Finite time horizon for the strategies

$\mathrm{t}$ : An instant of time in the dynamic game setup

$\mathrm{I}(\mathrm{t})$ :Risky innovation stock

$\mathrm{J}(\mathrm{t})$ : Risk less "ordinary" stock

$\mathrm{u}(\mathrm{t})$ : Investment in breakthrough innovation efforts (risky investments)

$\mathrm{g}(\mathrm{t})$ : Investment in quality, labor and capital (risk-free investments)

W: Wiener process or Brownian motion

$\{\Omega, F(t), P\}:$ Filtered probability space

$\mathrm{F}(\mathrm{t})$ : P.-augmentation of the natural filtration $\mathrm{F}^{\mathrm{W}}(\mathrm{t}):=\sigma\left(\mathrm{W}_{\mathrm{S}}{ }^{\mathrm{u}}\right.$, $\left.\mathrm{W}_{\mathrm{B}}{ }^{\mathrm{u}} ; 0 \leq \mathrm{u} \leq \mathrm{t}\right)$

$\theta$ : risk-adjusted return on investments in innovation

$\rho$ : Correlation coefficient between the Wiener processes

$\mathrm{W}_{\mathrm{B}}(\mathrm{T})$ and $\mathrm{Ws}(\mathrm{T})$ for the buyer's and supplier's overall gain processes

$\mathrm{r}$ : Rate of return on risk-free investments

$\sigma$ : A function defined on $\Omega$

$\mathrm{X}_{\mathrm{t}}^{\mathrm{u}}$ : Overall gain at time $\mathrm{t}$. It represents a diffusion process controlled by supplier

$\mathrm{X}_{\mathrm{t}}^{\mathrm{uS}}$ and buyer $\mathrm{X}_{\mathrm{t}}^{\mathrm{uB}}$.

$\mathrm{Zt}^{\mathrm{uS}, \mathrm{uB}}:=\mathrm{X}_{\mathrm{t}}^{\mathrm{uS}} / \mathrm{X}_{\mathrm{t}}^{\mathrm{uB}}$ is a jointly controlled diffusion process

which is a function of the investment policies $u_{S}$ and $u_{B}$.

$\tau_{\mathrm{y}}{ }^{\mathrm{uS}, \mathrm{uB}}:=\inf \left\{\mathrm{t}>0: \mathrm{Zt}^{\mathrm{uS}, \mathrm{uB}}=\mathrm{y}\right\}$. The first hitting time to the point $y$ under the specific investment policies $u_{S}$ and $u_{B}$.

$\mathrm{v}^{\mathrm{uS}, \mathrm{uB}}(\mathrm{z})$ : expected payoff function under the policy pair $\left(\mathrm{u}_{\mathrm{S}}, \mathrm{u}_{\mathrm{B}} \cdot\right)$

$\mathrm{p}(\mathrm{z})$ :"price" that a supplier can demand based on her overall wealth accumulation $\mathrm{h}(\mathrm{z}):$ a known function for $\mathrm{z}=\mathrm{a}$, $\mathrm{z}=\mathrm{b}$, with $\mathrm{h}(\mathrm{b})<\infty$

Following Myerson [10]we assume that the partnership formation game is such that each firm simultaneously announces the set of firms it wishes to ally with. Upon entering an alliance firms bargain over profit shares, and they write the results of the bargaining in a verifiable and enforceable contract. We can then assume that the compatibility costs are split evenly since bargaining can provide any other split through a transfer of profits.

The model considers two investment opportunities for the buyer and the supplier firm: investment in innovation stock $I(t)$ and investment in risk free "ordinary" stock $\mathrm{J}(\mathrm{t})$. The growth process of innovation stock for the supplier and the buyer firm is assumed to follow a geometric Brownian motion and $\mathrm{I}(\mathrm{t})$ satisfies the stochastic differential equation for supplier $\mathrm{S}$ and buyer B.

$$
\begin{aligned}
& d_{S}(t)=\mu_{S} I_{S}(t) d t+\sigma_{S} I_{S}(t) d W s(t) \\
& d I_{B}(t)=\mu_{B} I_{B}(t) d t+\sigma_{B} I_{B}(t) d W_{B}(t)
\end{aligned}
$$

where $\mu_{i}, i=B$. S are positive constants. The risk-free ordinary stock is assumed to evolve according to:

$$
\begin{aligned}
\mathrm{dJ}_{\mathrm{S}}(\mathrm{t}) & =\mathrm{rJ}_{\mathrm{S}}(\mathrm{t}) d \mathrm{t} \\
\mathrm{dJ}_{\mathrm{B}}(\mathrm{t}) & =r \mathrm{JJ}_{\mathrm{B}}(\mathrm{t}) d \mathrm{t}
\end{aligned}
$$

where $r \geq 0$. To avoid a trivial solution, we assume $\mu_{\mathrm{i}}>\mathrm{r}$, for $\mathrm{i}$ $=\mathrm{S}$, B since if $\mu_{\mathrm{i}}<\mathrm{r}$ then the firms would invest in risk-free investments, which yield higher returns. Let the parameter $\theta_{i}$ denote the risk-adjusted excess return of innovation stock $I_{i}(t)$ over the risk-free rate of return, for $i=S, B$. Specifically,

$$
\theta_{i}=\left(\mu_{i}-r\right) / \sigma_{i} \text { for } i=S, B
$$

Let $u_{S}(t)$ denote supplier's overall investments in innovation at time $\mathrm{t}$ under an investment policy $\mathrm{u}_{\mathrm{S}}=\mathrm{u}_{\mathrm{S}}(\mathrm{t}), \mathrm{t} \geq 0$, and similarly, let $\mathrm{u}_{\mathrm{B}}(\mathrm{t})$ denote buyer's investments in innovation at time $t$ under an investment policy $u_{B}=u_{B}(t), t>0$. It is assumed that both $u_{S}(t), t>0$ and $u_{B}(t), t>0$ are suitable admissible $F(t)-$ adapted control processes. In other words, $\mathrm{u}_{\mathrm{S}}(\mathrm{t})$, and $\mathrm{u}_{\mathrm{B}}(\mathrm{t})$, are non-anticipative functions that satisfy $\int_{0}^{\mathrm{T}} \mathrm{u}_{\mathrm{S}}^{2} \mathrm{dt}$ and $\int_{0}^{\mathrm{T}} \mathrm{u}_{\mathrm{B}}^{2} \mathrm{dt}<$ $\infty$ for every $\mathrm{T}<\infty$. The values of $\mathrm{u}_{\mathrm{S}}(\mathrm{t})$, and $\mathrm{u}_{\mathrm{B}}(\mathrm{t})$ are restricted to non-negative values.

Let $\mathrm{X}_{\mathrm{t}}^{\mathrm{uS}}$ denote the overall gain of the supplier firm at time $t$, if the firm follows policy $u_{S}=u_{S}(t), t \geq 0$ with $x(0)=x_{0}$. This overall payoff includes monetary benefits associated with these investments, for example, increased revenue, profits and non-monetary benefits such as channel power owing to innovation. It is assumed that the proportion of investment not invested in innovation is put into risk free investment options. The evolution of the process can thus be obtained from (1) and (2) and using the definition in (3). The equation can be written as:

$$
\begin{gathered}
d X_{t}^{u S}=u_{S}(t) X_{t}^{u S} d I_{S}(t) / I_{S}(t)+X_{t}^{u S}\left[1-u_{S}(t)\right] d J_{S}(t) / J_{S}(t) \\
=X_{t}^{u S}\left[\left(r+u_{S}(t) \sigma_{S} \theta_{S}\right) d t+u_{S}(t) \sigma_{S} d W_{S}(t)\right] \\
0 \leq u_{S}(t) \leq 1 \forall t
\end{gathered}
$$

Analogously, the equation for the buyer can be obtained as follows:

$$
\begin{gathered}
\mathrm{d} \mathrm{X}_{\mathrm{t}}^{\mathrm{uB}}=\mathrm{u}_{\mathrm{B}}(\mathrm{t}) \mathrm{X}_{\mathrm{t}}^{\mathrm{uB}} \mathrm{dI}_{\mathrm{B}}(\mathrm{t}) / \mathrm{I}_{\mathrm{B}}(\mathrm{t})+\mathrm{X}_{\mathrm{t}}^{\mathrm{uB}}\left[1-\mathrm{u}_{\mathrm{B}}(\mathrm{t})\right] \mathrm{dJ}_{\mathrm{B}}(\mathrm{t}) / \mathrm{J}_{\mathrm{B}}(\mathrm{t}) \\
=\mathrm{X}_{\mathrm{t}}^{\mathrm{uB}}\left[\left(\mathrm{r}+\mathrm{u}_{\mathrm{B}}(\mathrm{t}) \sigma_{\mathrm{B}} \theta_{\mathrm{B}}\right) \mathrm{dt}+\mathrm{u}_{\mathrm{B}}(\mathrm{t}) \sigma_{\mathrm{B}} \mathrm{dW}_{\mathrm{B}}(\mathrm{t})\right] \\
0 \leq \mathrm{u}_{\mathrm{B}}(\mathrm{t}) \leq 1 \forall \mathrm{t}
\end{gathered}
$$


These equations representing supplier's and buyer's individually controlled overall gain processes are similar to stochastic wealth equations familiar from financial economics (Huang and Litzenberger [11]).

In a supply chain environment the investments in innovation by buyer and supplier firm are expected to be correlated. To allow for this requirement, $\mathrm{W}_{\mathrm{S}}(\mathrm{t})$ is considered to be correlated with $\mathrm{W}_{\mathrm{B}}(\mathrm{t})$ with the correlation coefficient $\rho$, that is, $E\left(W_{S}(t), W_{B}(t)\right)=\rho t$. In this illustration we observe that $\mathrm{Xt}^{\mathrm{uS}}$ is the diffusion process controlled by supplier and $\mathrm{X}_{\mathrm{t}}^{\mathrm{uB}}$ is the diffusion process controlled by the buyer firm. The jointly controlled diffusion process can thus be defined as $\mathrm{Z}^{\mathrm{US}, \mathrm{uB}}:=$ $\mathrm{X}_{\mathrm{t}}^{\mathrm{uS}} / \mathrm{X}_{\mathrm{t}}^{\mathrm{uB}}$ where the supplier maximizes $\mathrm{Zt}^{\mathrm{uS}, \mathrm{uB}}:=\mathrm{X}_{\mathrm{t}}^{\mathrm{uS}} / \mathrm{X}_{\mathrm{t}}^{\mathrm{uB}}$ ${ }_{\mathrm{X} 2} \mathrm{t}$ and the buyer minimizes $\mathrm{Zt}^{\mathrm{uS}, \mathrm{uB}}$ by appropriate investments. It is a function of the investment policies $u_{S}$ and $\mathrm{u}_{\mathrm{B}}$.Applying Ito's lemma [12,p.80] and utilizing the results from (4) and (5) gives

$$
\begin{aligned}
& d \mathrm{Zt}^{\mathrm{uS}, \mathrm{uB}}=\mathrm{Zt}^{\mathrm{uS}, \mathrm{uB}}\left[\mathrm { m } \left(\mathrm{u}_{\mathrm{S}}(\mathrm{t}),\left(\mathrm{u}_{\mathrm{B}}(\mathrm{t})\right) \mathrm{dt}+\mathrm{u}_{\mathrm{S}}(\mathrm{t}) \sigma_{\mathrm{S}} \mathrm{dW}_{\mathrm{S}}(\mathrm{t})-\mathrm{u}_{\mathrm{B}}(\mathrm{t}) \sigma_{\mathrm{B}}\right.\right. \\
& \left.\mathrm{dW}_{\mathrm{B}}(\mathrm{t})\right]
\end{aligned}
$$

where the function $\mathrm{m}\left(\mathrm{u}_{\mathrm{S}}(\mathrm{t}),\left(\mathrm{u}_{\mathrm{B}}(\mathrm{t})\right)\right.$ is defined as

$$
\begin{array}{r}
\mathrm{m}\left(\mathrm{u}_{\mathrm{S}}(\mathrm{t}),\left(\mathrm{u}_{\mathrm{B}}(\mathrm{t})\right) \equiv \mathrm{m}\left(\mathrm{u}_{\mathrm{S}}(\mathrm{t}),\left(\mathrm{u}_{\mathrm{B}}(\mathrm{t})\right): \sigma_{\mathrm{S}}, \sigma_{\mathrm{B}}, \theta_{\mathrm{S}}, \theta_{\mathrm{B}}, \rho\right)=\mathrm{u}_{\mathrm{S}}(\mathrm{t}) \sigma_{\mathrm{S}}\right. \\
\theta_{\mathrm{S}}-\mathrm{u}_{\mathrm{B}}(\mathrm{t}) \sigma_{\mathrm{B}} \theta_{\mathrm{B}}+\mathrm{u}_{\mathrm{B}}(\mathrm{t})^{2} \sigma^{2}{ }_{B}-\rho \sigma_{\mathrm{S}} \sigma_{\mathrm{B}} \theta_{\mathrm{B}} \mathrm{u}_{\mathrm{s}}(\mathrm{t}), \mathrm{u}_{\mathrm{B}}(\mathrm{t}) \quad(7)
\end{array}
$$

The state dynamics of the stochastic differential game is given by equation (6). For the process $\mathrm{Z}(\mathrm{t})$ in equation (6), let $\tau_{\mathrm{y}}^{\mathrm{uS}, \mathrm{uB}}:=\inf \left\{\mathrm{t}>0: \mathrm{Zt}^{\mathrm{uS}, \mathrm{uB}}=\mathrm{y}\right\}$ be the first hitting time to the point $y$ under the specific investment policies $u_{S}$ and $u_{B}$. For given number $\mathrm{a}, \mathrm{b}$ where $\mathrm{a}<\mathrm{Z}_{0}<\mathrm{b}$, let $\tau:=\min \left\{\tau_{\mathrm{a}}{ }^{\mathrm{uS}, \mathrm{uB}}, \tau_{\mathrm{b}}{ }^{\mathrm{uS}, \mathrm{uB}}\right.$ \} denote the first escape time for the interval $(a, b)$ under the policies $u_{S}$ and $u_{B}$. The escape time signifies the point at which either the supplier or buyer gains channel power due to innovation capabilities.

The objective functional under the policies $\mathrm{u}_{\mathrm{S}}$ and $\mathrm{u}_{\mathrm{B}}$ are defined as:

$$
\begin{aligned}
\mathrm{v}^{\mathrm{uS}, \mathrm{uB}}(\mathrm{z})= & \mathrm{E}_{\mathrm{Z}}\left(\int _ { 0 } ^ { \tau } \mathrm { p } ( \mathrm { Zt } \mathrm { t } ^ { \mathrm { uS } , \mathrm { uB } } ) \operatorname { e x p } \left\{\left(\int_{0}^{\mathrm{t}} \lambda\left(\mathrm{Zr}^{\mathrm{uS}, \mathrm{uB}}\right) \mathrm{dr}\right\} \mathrm{dt}+\right.\right. \\
& \mathrm{h}\left(\mathrm{Zt} \mathrm{t}^{\mathrm{uS}, \mathrm{uB}}\right) \exp \left\{-\left(\int_{0}^{\mathrm{t}} \lambda\left(\mathrm{Zr}^{\mathrm{uS}, \mathrm{uB}}\right) \mathrm{dr}\right\}\right)
\end{aligned}
$$

where $\lambda(z)$ is a given nonnegative function representing the discounting function. This function reflects a risk-adjusted discounting of the payoff function. For mathematical convenience we only consider the cases when the discounting function is a constant $\lambda$. The function $\mathrm{p}(\mathrm{z})$ is the "price" that a supplier can demand based on his overall wealth accumulation. We assume real bounded continuous functions, and $h(z)$ is a known function for $\mathrm{z}=\mathrm{a}$ or $\mathrm{b}$, with $\mathrm{h}(\mathrm{b})<\infty$. The function allows an investigation of discounted payoff and utility maximization games within the context of the above problem formulation. The supplier would choose a control function $\mathrm{u}_{\mathrm{S}}(\mathrm{t})$ in order to maximize $\mathrm{v}\left(\mathrm{Zt}^{\mathrm{tS}, \mathrm{uB}}\right)$ while simultaneously the buyer would choose a control function $\mathrm{u}_{\mathrm{B}}(\mathrm{t})$ to minimize $\mathrm{v}\left(\mathrm{Zt}^{\mathrm{uS}, \mathrm{uB}}\right)$.

Perfect, revelation of choices made by the buyer and the supplier firms is assumed. For the supplier firm the objective functional and state dynamics are

$$
\mathrm{v}^{\mathrm{uS}, \mathrm{uB}}\left(\mathrm{Zt}^{\mathrm{uS}, \mathrm{uB}}\right)=\max \mathrm{E}_{\mathrm{z}}\left(\int _ { 0 } ^ { \tau } \mathrm { p } ( \mathrm { Zt } ^ { \mathrm { uS } , \mathrm { uB } } ) \operatorname { e x p } \left\{\left(\int_{0}^{\mathrm{t}} \lambda\left(\mathrm{Zr}^{\mathrm{uS}, \mathrm{uB}}\right) \mathrm{dr}\right.\right.\right.
$$

$$
\} \mathrm{dt}+\mathrm{h}\left(\mathrm{Zt}^{\mathrm{uS}, \mathrm{uB}}\right) \exp \left\{-\left(\int_{0}^{\mathrm{t}} \lambda\left(\mathrm{Zr}^{\mathrm{uS}, \mathrm{uB}}\right) \mathrm{dr}\right\}\right)
$$

subject to (6).

For the buyer, the objective functional and the state dynamics can be written as:

$$
\begin{gathered}
\mathrm{v}^{\mathrm{uS}, \mathrm{uB}}\left(\mathrm{Zt}^{\mathrm{uS}, \mathrm{uB}}\right)=\min _{\mathrm{z}}\left(\int _ { 0 } ^ { \tau } \mathrm { p } ( \mathrm { Zt } ^ { \mathrm { uS } , \mathrm { uB } } ) \operatorname { e x p } \left\{\left(\int_{0}^{\mathrm{t}} \lambda\left(\mathrm{Zr}^{\mathrm{uS}, \mathrm{uB}}\right) \mathrm{dr}\right.\right.\right. \\
\} \mathrm{dt}+\mathrm{h}\left(\mathrm{Zt}^{\mathrm{uS}, \mathrm{uB}}\right) \exp \left\{-\left(\int_{0}^{\mathrm{t}} \lambda\left(\mathrm{Zr}^{\mathrm{uS}, \mathrm{uB}}\right) \mathrm{dr}\right\}\right)
\end{gathered}
$$

subject to (6).

\section{Analysis of the Model}

Two classes of games involving investments by supplier and buyer firms are considered. The first class of stochastic game considers the discounted payoff maximization (minimization) objectives [13]. In this class, first a stochastic differential game is considered in which the supplier tries to maximize the expected discounted gain that is achieved upon outperforming the buyer in innovation capability. The buyer at the same time tries to minimize this expected discounted gain to be accrued by the supplier. Since the structure of the differential game is symmetric for both the buyer and the supplier, a straightforward inference can be made for the case when the buyer is investing in innovation to minimize the potential loss if the supplier outperforms. In this class of games, the ratio of the two gains processes $\mathrm{Zt}^{\mathrm{uS}, \mathrm{uB}}:=\mathrm{X}_{\mathrm{t}}^{\mathrm{uS}} / \mathrm{X}_{\mathrm{t}}^{\mathrm{uB}}$ is a sufficient statistic to evaluate the investment strategies for the supplier and the buyer firms. This feature makes the objective functional to be dependent only on the gain process .

As an alternative formulation, the other game examined has time dependence that unlike the previous structure of the game allowing only one winner the results suggest the optimal strategies to be adopted by supplier and buyer firm have both firms try to outperform each other and thereby obtain overall surplus. In light of this argument, by making the strategies to be time-dependent, it shows that the relative utility gained by a supplier and buyer can be obtained at any time instant. In these types of games both buyer and supplier receive utility (or disutility) from the ratio of the gain processes (i.e., from the relative performance of their respective gains achieved by investment in innovation stock and in ordinary stock.) where the game is played for fixed duration of time. As in the previous class of games, in these games also the ratio $\mathrm{Zt}^{\mathrm{uS}, \mathrm{uB}}:=$ $\mathrm{X}_{\mathrm{t}}^{\mathrm{uS}} / \mathrm{X}_{\mathrm{t}}^{\mathrm{uB}}$ acts as the pertinent state variable

The proofs of the following theorems are given in the Appendix.

\subsection{Discounted Payoffs}

(1) Case A

Theorem 1. If the degree of market advantage of a supplier over a buyer denoted by $\delta$ satisfies the conditions $\delta^{-}>\delta>\delta^{+}$ where $\delta^{-}, \delta^{+}$are as defined by

$$
\delta^{-}(\lambda)=(\rho / 2)\left(1-\sqrt{ } 1+4 \lambda / \theta_{\mathrm{B}}{ }^{2}\right) \text { and } \delta^{+}(\lambda)=(\rho / 2)(1+\sqrt{ } 1+
$$

then the value of the discounted game 
$F^{*}(z)=\sup _{u S} \inf _{u B} E_{z}\left(e_{b}^{-\lambda \tau u S, u B}\right)=\inf _{u B} \sup _{u S} E_{z}\left(e_{b}^{-\lambda \tau u S, u B}\right)$, for

$$
\mathrm{z}<\mathrm{u}
$$

is given by

$$
F^{*}(z)=(z / u)^{\eta+} \text { for } z<u
$$

$\eta^{+}$is defined by

$\eta^{+,-}=\left[\theta_{\mathrm{B}}{ }^{2}\left(1-\delta^{2}\right) \pm \sqrt{ } \mathrm{D}\right] / 2\left[\theta_{\mathrm{B}}^{2}\left(1+\delta^{2}-2 \rho \delta\right)+2 \lambda\left(1-\rho^{2}\right)\right]($

and the associated saddle point is given by

$$
\begin{aligned}
\mathrm{u}_{\mathrm{S}}{ }^{*}(\mathrm{z}) & \left.=\left[\theta_{\mathrm{S}} / \sigma_{\mathrm{S}}\right]\left[(\rho / \delta-1) \eta^{+}-1\right] /\left(\left(1-\rho^{2}\right)\left(\eta^{+}\right)^{2}-1\right)\right], \\
\mathrm{u}_{\mathrm{B}}{ }^{*}(\mathrm{z}) & \left.=\left[\theta_{\mathrm{B}} / \sigma_{\mathrm{B}}\right]\left[(1-\rho \delta) \eta^{+}-1\right] /\left(\left(1-\rho^{2}\right)\left(\eta^{+}\right)^{2}-1\right)\right](13)
\end{aligned}
$$

(2) Case B

Theorem 2. If the degree of market advantage of a supplier over a buyer $\delta$ satisfies the conditions $\delta^{-}>\delta>\delta^{+}$where $\delta^{-}, \delta^{+}$ are as defined in (9), then the value of the discounted game (10) is given by

$$
F^{*}(z)=(z / u)^{\eta+}(1-p / \lambda)+p / \lambda \text { for } z<u(14
$$

$\eta^{+}$is defined in equation

$\eta^{+,-}=\left[\theta_{\mathrm{B}}^{2}\left(1-\delta^{2}\right) \pm \sqrt{ } \mathrm{D}\right] / 2\left[\theta_{\mathrm{B}}^{2}\left(1+\delta^{2}-2 \rho \delta\right)+2 \lambda\left(1-\rho^{2}\right)\right]$

and the associated saddle point is given by (13)

(3) Case C

Theorem 3. If the degree of market advantage of a supplier over a buyer $\delta$ satisfies the conditions $\delta^{-}>\delta>\delta^{+}$where $\delta^{-}, \delta^{+}$ are as defined in

$$
\begin{array}{r}
\delta^{-}(\lambda)=(\rho / 2)\left(1-\sqrt{ }\left(1+\left(4 \lambda / \theta_{\mathrm{B}}{ }^{2}\right)\left(\lambda-1 / 2 \rho^{2}\right)\right) \text { and } \delta^{+}(\lambda)=\right. \\
(\rho / 2)\left(1+\left(4 \lambda / \theta_{\mathrm{B}}^{2}\right)\left(\lambda-1 / 2 \rho^{2}\right)\right)
\end{array}
$$

and $\theta_{\mathrm{B}}, \rho$ satisfy the condition $\theta_{\mathrm{B}}^{2} \rho^{2} \geq 2$ then the value of the discounted game (9) is given by

$$
F^{*}(z)=(z / u)^{\eta+} \text { for } z<u(11
$$

$\eta^{+}$is defined in equation

$\eta^{+}=\left[\theta_{\mathrm{B}}^{2}\left(1-\delta^{2}\right) \pm \sqrt{ } \mathrm{D}\right] / 2\left[\theta_{\mathrm{B}}^{2}\left(1-\delta^{2}-2 \rho \delta\right)+2 \lambda\left(1-\rho^{2}\right)\right]$

and the associated saddle point is given by (13).

Corollary: If ${\theta_{\mathrm{B}}}^{2} \rho^{2}$ is equal to 2 , the results are identical to that in Case A.

However, more generally the relationship between $\theta_{B}$, the risk-adjusted return on investments in innovation for the buyer and $\rho$, the correlation coefficient between the Wiener processes $\mathrm{W}_{\mathrm{B}}(\mathrm{t})$ and $\mathrm{W}_{\mathrm{S}}(\mathrm{t})$ for the buyer's and seller's overall gain processes, can be written as

$$
\theta_{\mathrm{B}} \geq \sqrt{ } 2 / \rho .
$$

\subsection{Utility Maximization}

(4) Case A'

Theorem 4. If the buyer and supplier are competing in utility maximization objective by maximizing the terminal value with investment in innovation and the discounting factor is $\lambda$, then the competitively optimal strategies are given as:

$$
\begin{gathered}
\mathrm{u}_{\mathrm{SJ}}{ }^{*}(\mathrm{z})=\left[\theta_{\mathrm{S}} / \sigma_{\mathrm{S}}\right][(\rho / \delta-1) \alpha-1] /\left(\left(1-\rho^{2}\right)\left(\alpha^{2}-1\right)\right] \\
\left.\mathrm{u}_{\mathrm{BJ}}{ }^{*}(\mathrm{z})=\left[\theta_{\mathrm{B}} / \sigma_{\mathrm{B}}\right][(1-\rho \delta) \alpha-1] /\left(\left(1-\rho^{2}\right) \alpha^{2}-1\right)\right]
\end{gathered}
$$

and the value of the game $\mathrm{F}^{*}(\mathrm{t}, \mathrm{z})$ is given by where $\mathrm{F}(\mathrm{t}, \mathrm{z})=$ $\mathrm{e}^{\mathrm{q}(\alpha)(\mathrm{T}-\mathrm{t})} \mathrm{z}^{\alpha}$ where $\mathrm{q}(\alpha)$ is

$$
\begin{gathered}
\left.\mathrm{q}(\alpha):=\alpha \theta_{\mathrm{B}}^{2}\left[\left(1-\delta^{2}\right)-\alpha(1+\delta-2 \rho \delta)\right] / 2\left[\left(1-\rho^{2}\right) \alpha^{2}-1\right)\right] \\
-\lambda
\end{gathered}
$$

(5) Case B'

Theorem 5. If the buyer and supplier are competing in payoff maximization and terminal utility maximization objectives then the form of competitively optimal strategies are given by (18), (19), and the value of the game $F^{*}(t, z)$ is given by $F(t, z)=e^{q(\alpha)(T-t)} z^{\alpha}$ where

$$
\begin{gathered}
\left.\mathrm{q}(\alpha):=\alpha \theta_{\mathrm{B}}^{2}\left[\left(1-\delta^{2}\right)-\alpha(1+\delta-2 \rho \delta)\right] / 2\left[\left(1-\rho^{2}\right) \alpha^{2}-1\right)\right] \\
-\lambda+1
\end{gathered}
$$

\section{Discussion}

We can derive from the above results that in all the cases pertaining to discounted payoff game as well as the utility maximization game, the investments made by the supplier and buyer in innovation are directly proportional to the risk adjusted returns of these investments. This result is quite intuitive because, if the firms can extract better returns from risk-free investments they would indeed do so. Moreover, these investments are also inversely proportional to the variability associated with the returns. Further exploration can be carried out by evaluating investments $\propto \theta_{\mathrm{i}} / \sigma_{\mathrm{i}}, \mathrm{i}=\mathrm{B}, \mathrm{S}$

Substituting $\theta_{\mathrm{i}}=\left[\mu_{\mathrm{i}}-\mathrm{r}\right] / \sigma_{\mathrm{i}}, \mathrm{i}=\mathrm{B}, \mathrm{S}$ above leads to investments $\propto\left[\mu_{i}-r\right] / \sigma_{i}, I=B, S$

The expression suggests that a firm would consider investing in risky innovations if the risk-free rate of returns is high and if the variance in the evolution of innovation stock is low. The stationary Markov perfect Nash equilibrium results are time invariant and are characterized completely by the parameters of the model.

The impact of correlation between the growth of buyer's and supplier's innovation stock $\rho$ and the power advantage $\delta$ cannot be straightforwardly conjectured from the equilibrium expressions. The propositions obtained from further analysis provide some implications of $\rho$ and $\delta$ on the nature of relationship and innovation investment strategies.

When the stochastic processes are negatively correlated, the supplier will always have higher degree of advantage than the buyer firm because now the value of $\delta$ is strictly greater than 1 . An explanation for this is that with a negative correlation the two collaborating partners are creating substitute technologies. In such circumstance the result suggests that the gain that a supplier could achieve by creating technology which is potentially used by competitors of firm $\mathrm{B}$, is higher than what the buyer could achieve by locking out the existing supplier.

Case B investigates a situation, in which there is a constant 
"price" charged by the supplier.

With a negatively correlated gain process it can be argued that the supplier would channel the payoffs into creating substitute products and innovation. By doing so, the supplier could potentially increase the market through other competing buyer firms. On the other hand, with no incentive to influence the "price", the buyer would set her innovation efforts to zero. In contrast, in case A the "price" is set to 0 and therefore both supplier and buyer firms target their innovation investments to gain channel power. In such a hypothetical situation the buyer and supplier would invest a positive amount to ensure that they attain the degree of advantage in the channel at terminal time. In case $\mathrm{C}$, since the "price" is now influenced by the relative gain $\mathrm{Z}^{\mathrm{uS}, \mathrm{uB}}$, the buyer has incentive to invest and compete in the collaborative setup.

From these cases, some inference can be made. First, the onus lies on the buyer to create conditions for the supplier so that the investments are synergistic. As could be observed, owing to the certainty of attaining the degree of advantage, the supplier firm would prefer an uncorrelated or negatively correlated gain process. This suggests that for any buying firm that wishes to be successful in a collaborative relationship, an understanding must be developed about how to own and control critical assets that provide opportunities to create customer dependency and supplier 'lock-ins'. Such understanding normally requires a competence in effective demand, supply, procurement and strategy management.

The results and the discussion connect well with the literature on core capabilities [14]. An uncorrelated or negatively correlated gain process associated with investments in risky innovation by the supplier and buyer firm implies that the responsibilities of the two firms in a partnership are set a priori. This is particularly relevant to cases when the supplier is chosen based on certain unique capabilities. These capabilities could be patented or possibly protected owing to high costs associated with replication. Similarly, a negatively correlated Brownian motion could be conceptualized as a situation in which one of the two supply chain partners is investing to create substitute technology. In light of the above argument, a supplier would gain by making investments in innovation that are independent of the investments made by the buyer. Furthermore, a supplier would also gain by making investments in innovations that are possible substitutes of the buyer's product-process portfolio. On the other hand, the buyer firm would never gain the degree of advantage if the investments in innovation are such that either they are uncorrelated with the investments made by the supplier or alternately, if the investments are potentially aimed at creating a substitute to the suppliers offering.

\section{References}

[1] Williamson, O.E. Markets and Hierarchies: Analysis and Anti-trust Implications, The Free Press: New York (1975)

[2] Williamson, O.E. (The Economic Institutions of Capitalism, The Free Press: New York (1985),

[3] Williamson, O.E.'Strategy Research: Governance and Competence Perspectives', Strategic Management Journal 20, 1087-1109 (1999)

[4] Gottinger, H.W., Innovation, Technology and Hypercompetition, Routledge: London (2006)

[5] Fine, C,H, Clockspeed: Winning industry control in the age of temporary advantage, Perseus Publ.: New York (1999)

[6] Fisher,F.M., Gowan,J. and Greenwood,J.E., Folded, Spindled and Mutulated, Economic Analysis and U.S. v. IBM, MIT Press: Cambridge,Ma (1983)

[7] Cox, Andrew; Ireland, P., Lonsdale,C., Sanderson,J., Watson,G. , Supply chains, markets and power: Mapping buyer and supplier power regimes, Routledge :London, New York (2002)

[8] Browne,S., 'Stochastic Differential Portfolio Games', Journal of Applied Probability 37,126-147 (2000)

[9] Karatzas, I. 'Applications of Stochastic Calculus in Financial Economics', in J.S. Barras and V. Mirelli (eds.), Recent Advances in Stochastic Calculus, Springer: Berlin, 169-217 (1990)

[10] Myerson, R.( Game Theory: Analysis of Conflict, Harvard Univ. Press: Cambridge, Ma (1991)

[11] Huang,C. and Litzenberger,R., Foundations for Financial Economics, Elsevier: New York (1988)

[12] Malliaris, A. G. and Brock, W. A. Stochastic Methods in Economics and Finance, North Holland: Amsterdam (1982)

[13] Mertens, J.M., 'Stochastic Games', in Handbook of Game Theory, Vol. 3, (R. Aumann and S. Hart, eds.), Elsevier, North Holland: Amsterdam, New York, 1809-1832 (2002)

[14] Prahalad, C.K. and Hamel,G. , 'The Core Competence of the Corporation', Harvard Business Review , 79-91 (1990) 